\title{
Ascorbic acid interaction with phytol: a modulatory effects on the anti-pyretic activity of paracetamol in Swiss albino mice
}

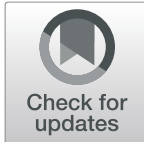

\author{
Md. Mizanur Rahaman' ', S. M. Hafiz Hassan' ${ }^{1}$, Miquel Martorell ${ }^{2,3}$, Javad Sharifi-Rad ${ }^{4}$ and \\ Muhammad Torequl Islam ${ }^{5,6^{*}}$ (D)
}

\begin{abstract}
Background: Antioxidants have protective capacity, and can be used combinedly with other substances. Both, ascorbic acid (AA) and phytol (PHY) have many important biological activities, including antioxidant, antiinflammatory, and organ protective activity. Recently, PHY has been found to exert an anti-pyretic effect in a mouse model. This study aims to evaluate the combined effects of AA and/or PHY with paracetamol (PARA) in Brewer's yeast-induced fever mice model.

Methods: AA (125 mg/kg) and/or PHY (200 mg/kg) were orally co-treated with the PARA (100 mg/kg, p.o.) in Brewer's yeast-induced fever Swiss mice. Data were analyzed by using GraphPadPrism software (version: 6.0), considering $p<0.05$ at 95\% confidence interval, and using one-way analysis of variance (ANOVA) through time, followed by Dunnett's post hoc multiple comparison test.

Results: PARA alone and with PHY and/or AA significantly $(p<0.05)$ reduced rectal temperature at 1 st h of observation. PHY reduced rectal temperature at 2 nd $h$, then maintained basal temperature over the observation period ( $4 \mathrm{~h}$ ). AA showed an insignificant anti-pyretic effect in experimental animals. However, in combination groups, AA (i.e., with PHY or PARA) did not found to interfere the PHY and PARA mediated reduction of rectal temperature in the animals. Furthermore, AA when co-treated with the PARA + PHY, it caused a slight hypothermic temperature at 1st $\mathrm{h}$, which was then started to restablish from 2 nd to $3 \mathrm{rd} h$, and normalized at 4 th $\mathrm{h}$.

Conclusion: Taken together, AA did not interfere anti-pyretic effects of PARA and PHY, suggesting its possible use as a combination substance.
\end{abstract}

Keywords: Mus musculus, Pyrexia, Ascorbic acid, Phytol, Paracetamol

\section{Introduction}

Paracetamol (also known as acetaminophen and APAP), a popular medication is used in pain and fever. It is typically used in mild to moderate pain $[8,23]$ and is often sold in combination with caffeine (augmenting analgesic and antipyretic effects), and other medications, including

\footnotetext{
* Correspondence: muhammad.torequl.islam@tdtu.edu.vn

${ }^{5}$ Laboratory of Theoretical and Computational Biophysics, Ton Duc Thang

University, Ho Chi Minh City 700000, Vietnam

${ }^{6}$ Faculty of Pharmacy, Ton Duc Thang University, Ho Chi Minh City 700000,

Vietnam

Full list of author information is available at the end of the article
}

psychoactive drugs and cold medications. Paracetamol (PARA) is also used for severe pain, cancer pain and pain after surgery, in combination with opioid pain medications. It has an oral (e.g., tablet, syrup), rectal (e.g., suppository) and injectable dosage forms [29]. Its effects generally last between 2 to $4 \mathrm{~h}$ and it is classified as a mild analgesic [29] rather than anti-inflammatory drug [22]. However, its exact mechanism of action is yet to be investigated [22]. Cumulative reports suggest that PARA acts through the cyclooxygenase (COX) pathway [2]. Ghanem et al. [10] suggests that PARA exerts an antipyretic effect through inhibiting the COX-2 enzyme. It 
may also inhibit prostaglandin synthesis in the central nervous system (CNS) [2]. However, the PARAassociated damage in the liver and kidney is currently a worldwide problem [4].

Phytol (PHY; 3,7,11,15-tetramethylhexadec-2-en-1-ol), a chlorophyll-derived diterpenoid is in the spotlight due to its diverse biological activities, suggesting a possibility in its biomedical application [17]. It has been seen to exhibit an anti-inflammatory effect through inhibiting neutrophil migration by a reduction in interleukin 1 beta (IL-1 $\beta$ ) and tumor necrosis factor alpha (TNF- $\alpha$ ) level and in a recent study, it has been found to exert an anti-pyretic effect in a dose-dependent manner in adult male Wistar rats [15]. In this study, the author suggests, via molecular docking study, that PHY may exert antipyretic effects through the 5IKR-dependent COX-2 inhibition pathway. On the other hand, ascorbic acid (AA, also called vitamin $C$ ), is a frequently used vitamin in human [19]. AA was initially identified as the factor preventing the scurvy disease, and became very popular for its antioxidant property. Although, the role of AA in prostaglandin synthesis has been yet to disclose [13] but it rabbits, anti-pyretic effect of PARA was potentiated by concomitant administration of this vitamin [6].

Oxidative stress seems to be involved in the toxicity of PARA [31] and the use of antioxidants with it has been found to reduce PARA-induced oxidative damage [12, 24]. Recently, the AA has been identified as an important vitamin that can be used to manage all stressful conditions linked to inflammatory processes and immunity, therefore, it can be considered as a combination component with other substances, including antioxidants and drugs [28]. This study aims to investigate the combined effects of AA and PHY on the standard anti-pyretic drug PARA in Brewer's yeast-induced fever mouse model.

\section{Materials and methods}

\section{Reagents and chemicals}

Brewer's yeast was purchased from the local market in Gopalganj, Bangladesh. PARA was kindly supplied by the Beximco Pharmaceuticals Ltd., Bangladesh, while the PHY was purchased from the Sigma-Aldrich (Chem Ex. Co. St. Louis, Missouri, USA). AA, tween 80 and $\mathrm{NaCl}$ were purchased from the Merck, India.

\section{Experimental animals}

Forty adult male albino mice (21-28 g), purchased from the animal resource branch of Jahangir Nagar University (JU), Dhaka, were used for this study. The animals were housed under standard environmental conditions (temperature: $25 \pm 2{ }^{\circ} \mathrm{C}$, humidity: $50 \pm 5 \%$, and $12 \mathrm{~h}$ light/dark cycles) in sanitized polypropylene cages containing sterile paddy husk as bedding. Animals were freely accessed to standard pellets as basal diet and water ad libitum. All the animals were acclimatized for 7 days before starting the study. The animals were randomized into experimental and control groups and the food was withdrawn $12 \mathrm{~h}$ before the treatment start.

\section{Groups and treatments (Brewer's yeast induced hyperthermia test in mice)}

This study was carried out by Brewer's yeast induced fever model described by Tomazetti et al. [30]. Rectal temperature (basal) was recorded of each mouse by using a clinical digital thermometer (MS Digital Thermometer, India). After basal rectal temperature measurement (temperature range 89.5 to $107.5^{\circ} \mathrm{F}$ ), fever was induced by subcutaneous injection of $15 \%(\mathrm{w} / \mathrm{v})$ suspension of Brewer's yeast in distilled water at a dose $10 \mathrm{~mL} /$ $\mathrm{kg}$ body weight (bw). Only mice, which rectal temperature increased at least $1^{\circ} \mathrm{F}\left(0.6^{\circ} \mathrm{C}\right)$ after $18 \mathrm{~h}$ of Brewer's yeast injection were selected to participate in the study (this temperature measurement was called 0 h). Selected animals were randomly divided into eight groups ( $n=5$, each group); treatment details have been shown in Table 1. PARA and PHY doses had been tested in a previous study [15]. After the treatment of samples/ controls, rectal temperature of each mouse was recorded at 1, 2, 3 and 4th hour.

\section{Statistical analysis}

All values are expressed as the mean \pm standard error of the mean (SEM) and the results were analyzed statistically by one-way analysis of variance (ANOVA) through time, followed by Dunnett's post hoc multiple comparison test by using GraphPadPrism software (version: 6.0, San Diego, California, USA. copyright $\odot$ 1994-1999), considering $p<0.05$ at $95 \%$ confidence interval.

\section{Results}

Table 2 suggests that oral administration of PARA 100 $\mathrm{mg} / \mathrm{kg}$ (bw) significantly $(\mathrm{p}<0.05)$ reduced rectal temperature at 1 st $\mathrm{h}$ and it maintained basal temperature during the observation period in animals. PHY at $200 \mathrm{mg} / \mathrm{kg}$ (bw) reduced rectal temperature at 2nd $h$, then it also maintained basal temperature over the observation period. No significant reduction of rectal temperature was seen in AA $(125 \mathrm{mg} / \mathrm{kg})$ group until 3rd h of observation. At 4th h AA was found to decrease the temperature slightly in the animals. However, AA in combination groups (AA + PHY and AA + PARA) did not interfere the PHY and PARA mediated reduction of rectal temperature in animals. Moreover, AA when cotreated with the PARA and PHY, it attained a slight hypothermic temperature at $1 \mathrm{st} \mathrm{h}$, and the basal temperature was then normalized at 4th $\mathrm{h}$. 
Table 1 Animals fasting overnight are treated with the following substances at $10 \mathrm{~mL} / \mathrm{kg}$

\begin{tabular}{ll}
\hline Treatment groups & Description \\
\hline Brewer's yeast subcutaneous injection & $15 \% \mathrm{w} / \mathrm{V}$ suspension \\
Gr-l: VEH (p.o.) & $10 \mathrm{~mL} / \mathrm{kg}$ bw (0.05\% Tween 80 dissolved in $0.9 \% \mathrm{NaCl}$ solution) \\
Gr-II: PARA (p.o.) & $100 \mathrm{mg} / \mathrm{kg}$ (dissolved in VEH) \\
Gr-III: PHY (p.o.) & $200 \mathrm{mg} / \mathrm{kg}$ (emulsified in VEH) \\
Gr-IV: AA (p.o.) & $125 \mathrm{mg} / \mathrm{kg}$ (emulsified in VEH) \\
Gr-V: PHY + AA (p.o.) & Gr-V to Gr-VIII PARA are administered after 15 min of PHY and/or AA administration \\
Gr-VI: PHY + PARA (p.o.) & \\
Gr-VII: AA + PARA (p.o.) & \\
Gr-VIII: PHY + AA + PARA (p.o.) & \\
\hline AA ascorbic acid, bw body weight, PARA paracetamol, PHY phytol, P.o. per-oral, VEH vehicle
\end{tabular}

$A A$ ascorbic acid, bw body weight, PARA paracetamol, $P H Y$ phytol, p.o. per-oral, $V E H$ vehicle

\section{Discussion}

The Brewer's yeast suspension induced pyrexia model is more commonly used to study the anti-pyretic potential of a wide variety of substances, including crude extracts or their derivatives, chemicals or drugs. In this model, pyrexia is produced due to an enhanced formation of proinflammatory mediators like IL- $1 \beta$ and TNF- $\alpha$, from the infected or damaged tissue(s), which stimulate synthesis of prostaglandin E2 (PG-E2) near preoptic hypothalamus area and triggers to rise body temperature [9, 22]. Natural products are used as a traditional tool for the treatment of various diseases [16].

PARA is commonly used to treat pain (mainly pain associated with osteoarthritis) and fever, especially of choice in patients that cannot be treated with nonsteroidal anti-inflammatory drugs (NSAIDs), such as people with bronchial asthma, peptic ulcer disease, hemophilia, salicylate-sensitized people, children under 12 years of age, pregnant or breastfeeding women [5, 18]. The mechanism of action of PARA is complex that includes the effects of both the peripheral (COX inhibition), and central (COX, serotonergic descending neuronal pathway, L-arginine/nitric oxide (NO) pathway, cannabinoid system) pathways. Although, PARA is well tolerated drug it produces some side effects in the gastrointestinal tract and hepatic system [18], thus its safety has questioned the validity of the sale of this drug without being a prescription [7]. In a PARA overdose situation, the metabolism of this drug (glucuronidation and sulfuration in the liver) is saturated and subsequently metabolized to $\mathrm{N}$-acetyl-p-benzoquinone imine (NAPQI) by cytochrome P450 [2]. NAPQI is a toxic substance which is safely reduced by glutathione $(\mathrm{GSH})$ to nontoxic substance. A PARA overdose depletes the GSH

Table 2 Anti-pyretic effects of phytol and/or ascorbic acid and controls in Brewer's yeast-induced pyrexia in mice

\begin{tabular}{|c|c|c|c|c|c|c|}
\hline \multirow[t]{2}{*}{ Treatment } & \multicolumn{6}{|c|}{ Rectal temperature $\left({ }^{\circ} \mathrm{F}\right)$} \\
\hline & Basal $^{\#}$ & oh $\left(\right.$ after $\left.18 h^{\# \#}\right)$ & $1 h^{\# \# \#}$ & $2 h^{\# \# \#}$ & $3 \boldsymbol{h}^{\# \# \#}$ & $4 h^{\# \# \#}$ \\
\hline Gr-I: Control $(n=5)$ & $98.50 \pm 0.18$ & $100.67 \pm 0.23$ & $100.77 \pm 0.14$ & $100.73 \pm 0.09$ & $100.63 \pm 0.18$ & $100.58 \pm 0.27$ \\
\hline Gr-II: PARA $(n=5)$ & $98.46 \pm 0.09$ & $100.40 \pm 0.09$ & $98.47 \pm 0.23^{* a c}$ & $99.37 \pm 0.12^{* a}$ & $98.41 \pm 0.31^{* a}$ & $98.46 \pm 0.37^{* a}$ \\
\hline Gr-III: PHY $(n=5)$ & $98.48 \pm 0.11$ & $100.48 \pm 0.17$ & $99.58 \pm 0.09^{a}$ & $98.48 \pm 0.23^{* a}$ & $98.38 \pm 0.12^{* a}$ & $98.44 \pm 0.09^{* a}$ \\
\hline Gr-IV: AA $(n=5)$ & $97.27 \pm 1.45$ & $97.93 \pm 1.49$ & $98.07 \pm 1.43^{\mathrm{a}}$ & $98.04 \pm 1.11^{\mathrm{a}}$ & $97.93 \pm 0.11^{a}$ & $97.83 \pm 0.47^{\mathrm{a}}$ \\
\hline Gr-V: $P H Y+A A(n=5)$ & $96.30 \pm 0.58$ & $97.37 \pm 0.33$ & $97.73 \pm 0.69^{\mathrm{ac}}$ & $96.33 \pm 1.16^{* a b c d}$ & $96.22 \pm 0.49^{* a b c d}$ & $97.31 \pm 0.35^{a b c}$ \\
\hline Gr-VI: PHY + PARA $(n=5)$ & $98.46 \pm 0.16$ & $100.50 \pm 0.11$ & $98.47 \pm 0.09^{* a c}$ & $98.45 \pm 0.06^{* a}$ & $98.42 \pm 0.09^{* a}$ & $98.47 \pm 0.14^{* a}$ \\
\hline Gr-VII: AA + PARA $(n=5)$ & $99.30 \pm 0.35$ & $99.90 \pm 0.26$ & $99.33 \pm 0.35^{a}$ & $99.26 \pm 0.18^{a}$ & $99.33 \pm 0.15^{a}$ & $99.29 \pm 0.20^{\mathrm{a}}$ \\
\hline Gr-VIII: PHY + AA + PARA $(n=5)$ & $99.93 \pm 0.76$ & $100.63 \pm 0.22$ & $99.83 \pm 0.59^{a}$ & $99.85 \pm 1.22^{\mathrm{a}}$ & $99.89 \pm 1.04^{a}$ & $99.92 \pm 1.51^{\mathrm{a}}$ \\
\hline
\end{tabular}

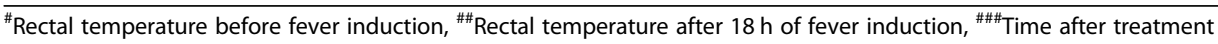

$A A$ ascorbic acid, PARA paracetamol, PHY phytol. Values are mean \pm SEM. Statistical analysis: ANOVA followed by Dunnett's multiple comparisons $p<0.05$ when compared to *0 $\mathrm{h}$ (respective group); ${ }^{\mathrm{a}}$ control, ${ }^{\mathrm{b}} \mathrm{PARA},{ }^{\mathrm{C}} \mathrm{PHY},{ }^{\mathrm{d}} \mathrm{AA}$

Gr-l: Control (vehicle)

Gr-II: PARA (100 mg/kg)

Gr-III: PHY $(200 \mathrm{mg} / \mathrm{kg})$

Gr-IV: AA $(125 \mathrm{mg} / \mathrm{kg})$

Gr-V: PHY $(200 \mathrm{mg} / \mathrm{kg})+$ AA $(125 \mathrm{mg} / \mathrm{kg})$

Gr-VI: PHY $(200 \mathrm{mg} / \mathrm{kg})+$ PARA $(100 \mathrm{mg} / \mathrm{kg})$

Gr-VII: AA (125 mg/kg) + PARA (100 mg/kg)

Gr-VIII: PHY $(200 \mathrm{mg} / \mathrm{kg})+$ AA $(125 \mathrm{mg} / \mathrm{kg})+$ PARA $(100 \mathrm{mg} / \mathrm{kg})$ 
stores, and once they reach less than $30 \%$ of normal, NAPQI levels increase and subsequently binds to hepatic macromolecules causing irreversible hepatic necrosis [11]. The reduction/restoration of oxidized glutathione (GSSG) is a crucial point to avoid PARA toxicity. AA restores GSH levels $[27,33]$ and may decrease PARA toxicity without decreasing its anti-pyretic effects.

It is evident that PARA's overdose can cause severe liver injury, liver necrosis and kidney damage in human beings and animals [4]. Overproduction of reactive oxygen and nitrogen species (ROS/RNS), and oxidative stress in such organs seems to be involved in PARA toxicity [31]. Antioxidants can be used as combination substances with PARA therapy, especially those having no antagonizing effects [26]. To date, a number of antioxidant molecules have been reported to counteract PARAinduced oxidative damages. Apigenin $(10 \mathrm{mg} / \mathrm{kg}$ bw for 6 days) inhibited lipid peroxidation and increased the enzymatic antioxidant defense mechanisms in PARAinduced hepatotoxicity in rats [26]. In adult male albino rats, curcumin pretreatment $(100 \mathrm{mg} / \mathrm{kg}$ bw for 7 days) prevented the toxic effects of PARA and inhibited the elevation of the total oxidant status and oxidant status index [3]. In mice, ginsenoside Rk1 (10 and $20 \mathrm{mg} / \mathrm{kg}$ bw for 7 days) ameliorates PARA-induced hepatoxicity via antioxidantion, anti-inflammation, antinitrative, and antiapoptosis mechanisms [14]. In a recent study, AA ( $500 \mathrm{mg} / \mathrm{kg}$ bw for 8 days) has been found to protect PARA-induced oxidative liver damage in rats [1]. In another study, AA ( $100 \mathrm{mg} / \mathrm{kg}$ bw for 3 days) amplified the antioxidant defense potential and exhibited a strong hematoprotective effect against PARA-induced damaging effects in rats, suggesting a promising cotherapeutic option with this drug [21]. In this study, AA did not interfere anti-pyretic effects of PARA.

Cumulative evidence suggests that diterpenes are protective in nature and can be used to protect oxidative damage caused by PARA [34]. In some studies, it has been suggested that diterpenes have the painkiller capacity [25] and can be co-treated with PARA to treat many diseases, including cancers [20,32]. In our study, PHY was found to exert a significant anti-pyretic effect in mice, which is an agreement with the report suggested by Islam [15]. Moreover, PHY did not antagonize PARA-mediated anti-pyretic effect in the experimental animals, neither its activity encountered by AA. Interestingly, PHY when combined with the AA and PARA, it reduced the rectal temperature in experimental animals.

\section{Conclusion}

AA did not exhibit anti-pyretic effect in Brewer's yeastinduced fever mice model. PHY reduced rectal temperature at $2 \mathrm{nd} \mathrm{h}$ and maintained the thermal balance like the basal temperature throughout the observation period (4h). AA and/or PHY did not interfere PARA-mediated anti-pyretic effects in the experimental animals. Furthermore, AA and PHY when cotreated with the PARA a significant reduction of rectal temperature was seen in the animals. It may be due to a synergistic effect by the AA and PHY on the anti-pyretic effect of PARA. Further studies are necessary to understand the possible mechanism of action behind this combined anti-pyretic effect. Moreover, new studies are needed to evaluate a possible lower toxicity of these treatments.

\section{Acknowledgements}

We are owed to the Department of Pharmacy, Life Science Faculty, Bangabandhu Sheikh Mujibur Rahman Science and Technology University (BSMRSTU), Gopalganj-8100, Bangladesh for providing the laboratory facilities to conduct this study. Miquel Martorell would to thanks CONICYT PIA/APOYO CCTE AFB170007.

\section{Authors' contributions}

MMR- Laboratory work, data collection \& writing of primary draft; SMHH Data collection \& writing of primary draft; MM- Final drafting and revision; JSR- Final drafting and revision; MTI- Study design, data manipulation and analysis, writing of the final draft.

\section{Funding}

Not applicable.

\section{Availability of data and materials}

Not applicable.

\section{Ethics approval and consent to participate}

This project was approved by the Department of Pharmacy (Approval No. 20151209020), BSMRSTU, Gopalganj-8100, Bangladesh.

\section{Consent for publication}

The authors declare their consent for publication.

\section{Competing interests}

The authors declare no conflicts of interest.

\section{Author details}

'Department of Pharmacy, Life Science Faculty, Bangabandhu Sheikh Mujibur Rahman Science and Technology University, Gopalganj, (Dhaka) 8100, Bangladesh. ${ }^{2}$ Department of Nutrition and Dietetics, Faculty of Pharmacy, and Centre for Healthy Living, University of Concepción, Concepción, Chile. ${ }^{3}$ Unidad de Desarrollo Tecnológico, UDT, Universidad de Concepción, Concepción, Chile. ${ }^{4}$ Phytochemistry Research Center, Shahid Beheshti University of Medical Sciences, Tehran, Iran. ${ }^{5}$ Laboratory of Theoretical and Computational Biophysics, Ton Duc Thang University, Ho Chi Minh City 700000, Vietnam. ${ }^{6}$ Faculty of Pharmacy, Ton Duc Thang University, Ho Chi Minh City 700000, Vietnam.

Received: 25 September 2019 Accepted: 6 August 2020

Published online: 12 August 2020

\section{References}

1. Abdulrazzaq AM, Badr M, Gammoh O, Abu Khalil AA, Ghanim BY, Alhussainy TM, Qinna NA. Hepatoprotective actions of ascorbic acid, alpha lipoic acid and silymarin or their combination against acetaminophen-induced hepatotoxicity in rats. Medicina (Kaunas). 2019;55(5):181. https://doi.org/10. 3390/medicina55050181.

2. Agrawal S, Khazaeni B. Acetaminophen toxicity. In: StatPearls. Treasure Island: StatPearls Publishing; 2020.

3. Ahmad MM, Rezk NA, Fawzy A, Sabry M. Protective effects of curcumin and silymarin against paracetamol induced hepatotoxicity in adult male albino rats. Gene. 2019;712:143966. 
4. Brune K, Renner B, Tiegs G. Acetaminophen/paracetamol: a history of errors, failures and false decisions. Eur J Pain. 2015;19(7):953-65.

5. Crofford LJ. Use of NSAIDs in treating patients with arthritis. Arthritis Res Ther. 2013;15(Suppl 3):S2. https://doi.org/10.1186/ar4174.

6. Dange SV, Shah KU, Ghongane BB, Ranade RS. Potentiation of antipyretic effect of acetaminophen by concomitant administration of ascorbic acid. Indian J Physiol Pharmacol. 1985;29(2):129-31.

7. Dart RC, Green JL. The prescription paradox of acetaminophen safety. Pharmacoepidemiol Drug Saf. 2016;25(5):599-601.

8. de Martino M, Chiarugi A. Recent advances in pediatric use of oral paracetamol in fever and pain management. Pain Ther. 2015;4(2):149-68

9. Garami A, Steiner AA, Romanovsky AA. Fever and hypothermia in systemic inflammation. Handb Clin Neurol. 2018;157:565-97.

10. Ghanem Cl, Pérez MJ, Manautou JE, Mottino AD. Acetaminophen from liver to brain: new insights into drug pharmacological action and toxicity. Pharmacol Res. 2016;109:119-31.

11. Guengerich FP. Cytochrome P450 2E1 and its roles in disease. Chem Biol Interact. 2020;322:109056

12. Harman AW. The effectiveness of antioxidants in reducing paracetamolinduced damage subsequent to paracetamol activation. Res Commun Chem Pathol Pharmacol. 1985;49(2):215-28.

13. Horrobin DF. Ascorbic acid and prostaglandin synthesis. Subcell Biochem. 1996:25:109-15

14. Hu JN, Xu XY, Li W, Wang YM, Liu Y, Wang Z, Wang YP. Ginsenoside Rk1 ameliorates paracetamol-induced hepatotoxicity in mice through inhibition of inflammation, oxidative stress, nitrative stress and apoptosis. J Ginseng Res. 2019:43(1):10-9.

15. Islam MT. Antipyretic effect of phytol, possibly via 5KIB-dependent COX-2 inhibition pathway. Inflammopharmacology. 2019;27(4):857-62.

16. Islam MT, Ali ES, Uddin SJ, Shaw S, Islam MA, Ahmed MI, Shill MC, Karmakar UK, Yarla NS, Khan IN, Billah MM, Pieczynska MD, Zengin G, Malainer C, Nicoletti F, Gulei D, Berindan-Neagoe I, Apostolov A, Banach M, Yeung AWK, El-Demerdash A, Xiao J, Dey P, Yele S, Jóźwik A, Strzałkowska N, Marchewka J, Rengasamy KRR, Horbańczuk J, Kamal MA, Mubarak MS, Mishra SK, Shilpi JA, Atanasov AG. Phytol: a review of biomedical activities. Food Chem Toxicol. 2018;121:82-94.

17. Islam MT, Sarkar C, El-Kersh DM, Jamaddar S, Uddin SJ, Shilpi JA, Mubarak MS. Natural products and their derivatives against coronavirus: A review of the non-clinical and pre-clinical data. Phytother Res. 2020. https://doi.org/10. 1002/ptr.6700

18. Jóźwiak-Bebenista M, Nowak JZ. Paracetamol: mechanism of action, applications and safety concern. Acta Pol Pharm. 2014;71(1):11-23.

19. Knight J, Madduma-Liyanage K, Mobley JA, Assimos DG, Holmes RP. Ascorbic acid intake and oxalate synthesis. Urolithiasis. 2016;44(4):289-97.

20. Lee $\mathrm{R}$, Wen A, Berube C. Moxifloxacin-acetaminophen-warfarin interaction during bacille Calmette-Guerin treatment for bladder cancer. Am J Health Syst Pharm. 2011;68(9):814-7.

21. Matić MM, Paunović MG, Milošević MD, Ognjanović BI, Saičić ZS Hematoprotective effects and antioxidant properties of $\beta$-glucan and vitamin C against acetaminophen-induced toxicity: an experimental study in rats. Drug Chem Toxicol. 2019;18:1-8.

22. McKay GA, Walters MR. Non-opioid analgesics. Lecture notes clinical pharmacology and therapeutics. 9th ed. Hoboken: Wiley; 2013. ISBN 9781118344897

23. Meremikwu M, Oyo-Ita A. Paracetamol for treating fever in children. Cochrane Database Syst Rev. 2002;2002(2):CD003676. https://doi.org/10. 1002/14651858.CD003676.

24. Mohamad NE, Yeap SK, Lim KL, et al. Antioxidant effects of pineapple vinegar in reversing of paracetamol-induced liver damage in mice. Chin Med. 2015;10:3.

25. Nesterova Y, Povet'yeva TN, Suslov NI, Zyuz'kov GN, Pushkarskii SV, Aksinenko SG, Schultz EE, Kravtsova SS, Krapivin AV. Analgesic activity of diterpene alkaloids from Aconitum baikalensis. Bull Exp Biol Med. 2014; 157(4):488-91.

26. Rašković A, Gigov S, Čapo I, Paut Kusturica M, Milijašević B, Kojić-Damjanov S, Martić N. Antioxidative and protective actions of Apigenin in a paracetamol-induced hepatotoxicity rat model. Eur J Drug Metab Pharmacokinet. 2017;42(5):849-56.

27. Shang F, Lu M, Dudek E, Reddan J, Taylor A. Vitamin C and vitamin E restore the resistance of GSH-depleted lens cells to H2O2. Free Radic Biol Med. 2003;34(5):521-30
28. Sorice A, Guerriero E, Capone F, Colonna G, Castello G, Costantini S. Ascorbic acid: its role in immune system and chronic inflammation diseases. Mini-Rev Med Chem. 2014;14(5):444-52.

29. Tobias J, Hochhauser D. Cancer and its management. Hoboken: Wiley; 2014. p. 119. ISBN 9781118468715

30. Tomazetti J, Avila DS, Ferreira AP, Martins JS, Souza FR, Royer C, Rubin MA Oliveira MR, Bonacorso HG, Martins MA, Zanatta N, Mello CF. Baker yeastinduced fever in young rats: characterization and validation of an animal model for antipyretics screening. J Neurosci Methods. 2005;147(1):29-35.

31. Wang X, Wu Q, Liu A, Anadón A, Rodríguez JL, Martínez-Larrañaga MR, Yuan Z, Martínez MA. Paracetamol: overdose-induced oxidative stress toxicity, metabolism, and protective effects of various compounds in vivo and in vitro. Drug Metab Rev. 2017;49(4):395-437.

32. Wu YJ, Neuwelt AJ, Muldoon LL, Neuwelt EA. Acetaminophen enhances cisplatin- and paclitaxel-mediated cytotoxicity to SKOV3 human ovarian carcinoma. Anticancer Res. 2013;33(6):2391-400.

33. Xu P, Li Y, Yu Z, Yang L, Shang R, Yan Z. Protective effect of Vitamin C on Triptolide-induced acute hepatotoxicity in mice through mitigation of oxidative stress. An Acad Bras Cienc. 2019;91(2):e20181257.

34. Yoshioka H, Aoyagi Y, Fukuishi N, Gui MY, Jin YR, Li XW, Adachi Y, Ohno N, Takeya K, Hitotsuyanagi Y, Miura N, Nonogaki T. Suppressive effect of kamebakaurin on acetaminophen-induced hepatotoxicity by inhibiting lipid peroxidation and inflammatory response in mice. Pharmacol Rep. 2017; 69(5):903-7.

\section{Publisher's Note}

Springer Nature remains neutral with regard to jurisdictional claims in published maps and institutional affiliations.

\section{Submit your manuscript to a SpringerOpen ${ }^{\circ}$ journal and benefit from:}

- Convenient online submission

- Rigorous peer review

- Open access: articles freely available online

- High visibility within the field

- Retaining the copyright to your article

Submit your next manuscript at $\boldsymbol{\nabla}$ springeropen.com 